\title{
Synthesis of Sn-3.5Ag Alloy Nanosolder by Chemical Reduction Method
}

\author{
Hsin Jen Pan ${ }^{1}$, Chao Yang Lin ${ }^{1 *}$, Udit Surya Mohanty ${ }^{2 *}$, Jung Hua Chou ${ }^{1}$ \\ ${ }^{1}$ Department of Engineering Science, National Cheng Kung University, Tainan, Chinese Taipei; ${ }^{2}$ Department of Materials Science \\ and Engineering, National Cheng Kung University, Chinese Taipei. \\ Email: *n9895121@mail.ncku.edu.tw, *suryaudit@yahoo.com
}

Received June $6^{\text {th }}, 2011$; revised August 22 ${ }^{\text {nd }}, 2011$; accepted September $20^{\text {th }}, 2011$.

\begin{abstract}
The synthesis of Sn-3.5Ag alloy nanosolder was investigated by chemical reduction method. In this method, chemical precipitation was achieved by using sodium $\mathrm{NaBH}_{4}$ as a reducing agent and PVP (poly-m-vinyl 2-pyrrolidone) as a stabilizer. The experimental results obtained with different amounts of $\mathrm{NaBH}_{4}$ and $\mathrm{PVP}$ were compared. X-ray diffraction $(X R D)$ patterns revealed that $\mathrm{Ag}_{3} \mathrm{Sn}$ was formed due to the successful alloying process. Scanning Electron Microscopy (SEM) and Transmission Electron Microscopy (TEM) demonstrated a change in the morphology of Sn-3.5Ag alloy nanosolder with increase in the PVP content in the bath. The size of the nanoparticles ranged from 300 to $700 \mathrm{~nm}$. The nanosolder/nanoparticles were thus synthesized successfully under controlled and optimized chemical reduction process.
\end{abstract}

Keywords: Alloy, Agglomeration, Nanoparticles, Chemical Reduction, Morphology, X-Ray Diffraction

\section{Introduction}

The electronics industry has grown rapidly since the 1960s and the corresponding process technology for integrated circuits (IC) has also become more complicated [1]. One of the most important challenges faced by the electronics industry is the technology of IC devices packaging, with regards to the electrical connectivity and environmental protection. Presently, one of the most important package materials is the development of solder alloy. The cost of the solder needs to be low and the performance needs to be higher [2] for better reliability. $\mathrm{SnPb}$ solders have long been used as interconnect materials in microelectronic packaging. Due to the health threat of lead to human beings, the use of lead-free interconnect materials is imperative. In the last few years tin/silver $(96.5 \mathrm{Sn} 3.5 \mathrm{Ag}$ ) has been one of the promising alternatives for $\mathrm{Sn} / \mathrm{Pb}$ solders [3]. However, the melting point $(\mathrm{Tm})$ of $96.5 \mathrm{Sn} 3.5 \mathrm{Ag}$ alloy $\left(222^{\circ} \mathrm{C}\right)$ is more than $30^{\circ} \mathrm{C}$ ) higher than that of eutectic $\mathrm{Sn} / \mathrm{Pb}$ solders $\left(183^{\circ} \mathrm{C}\right)$. The high $T \mathrm{~m}$ requires a higher reflow temperature in the electronics manufacturing process. This high process temperature in electronics assembly has adverse effects not only on energy consumption, but also on substrate warpage, thermal stress and popcorn cracking in molded components, resulting in poor reliability of the devices. As such, studies on lowering the processing temperature of the lead-free metals are our main interest. The melting point can be dramatically decreased when the size of substances is reduced to nanometer size [4]. At present, the size dependent melting behavior of metal nanoparticles has been found both theoretically and experimentally [5-10]. The high ratio of surface area to volume of nano particles has been known as one of the driving forces for the size dependent melting point depression. Duh et al. [11] has demonstrated successfully the synthesis of Sn-3.5Ag- $x \mathrm{Cu}(x=0.2,0.5,1.0)$ nanoparticles by chemical precipitation with $\mathrm{NaBH}_{4}$ for lead-free solder applications. They have successfully shown the melting by differential scanning calorimetry (DSC) of their synthesized $\mathrm{SnAgCu}$ alloy nanoparticles. However, no obvious melting point depression behavior was observed, which might be due to the surface oxidation or heavy agglomeration of their synthesized nanoparticles. The solder alloy powders have been synthesized by various methods such as solid state melting process [12], electrolytic deposition [13] and chemical reduction [14]. The solid state melting process is a commonly used technique but the limitation is the minimum powder size. The minimum size obtained is about $100 \mathrm{~nm}$ even when treated by 
advanced grinding techniques [15]. Nevertheless, chemical reduction technique can produce high quality micro and nano scale powders, especially gold and silver nano particles $[16,17]$. The advantages of the reduction process are its lower cost, greater convenience and capability of producing smaller powders. Chemical methods have emerged to be indispensable for synthesizing nanocrystals of various types of materials. These methods are generally carried out under mild conditions and are relatively straightforward. Nanodimensional materials in the form of embedded solids, liquids, and foams have also been prepared by chemical means and such materials have been in use for some time [18-20]. El Sayed and co-workers [21] used simultaneous reduction of silver and gold salt to form $\mathrm{Ag} / \mathrm{Au}$ alloy nanoparticle with size of $1 \mathrm{~nm}$ and less than $10 \mathrm{~nm}$, respectively. The synthesis of $\mathrm{Sn}-\mathrm{Sb}$ microcrystalline powders with a particle size of $<300 \mathrm{~nm}$ has also been reported [22] by using $\mathrm{NaBH} 4$ as a reducing agent.

The present paper investigates the synthesis of Sn-3.5 Ag alloy nanosolder/nanoparticles by chemical reduction techniques in presence of stabilizer PVP.

\section{Experimental}

The stoichiometric amounts of the salts i.e. $\mathrm{SnSO}_{4}$ and $\mathrm{AgNO}_{3}$ were procured from (Shimakyu's Pure Chemicals, Japan) and were dissolved in aqueous solution as the metal precursors. $\mathrm{NaBH}_{4}$ and poly (m-vinyl 2-pyrrolidone) (PVP) were obtained from Pancreac Sintesis and from Alfa Aesar respectively. Solutions of the metal precursors were rapidly added to $\mathrm{NaBH}_{4}, \mathrm{PVP}$, and $\mathrm{NaOH}$ (from Wako Pure Chemical Industries) solutions under rapid stirring for $3-4 \mathrm{~h}$. The stirring time was varied from $12 \mathrm{~h}$ to $48 \mathrm{~h}$ to ensure complete reduction. After stirring the black precipitates obtained were washed several times with distilled water and filtered until the filtrate $\mathrm{pH}$ was the same as that of distilled water and filtered. The precipitates or powders were then dried in an oven maintained at $40^{\circ} \mathrm{C}$ for $12 \mathrm{~h}$. The morphologies of the synthesized nanosolders/ nanoparticles were investigated by using TEM (Transmission electron microscopy, JEOL JEM-2100, Japan) and SEM (scanning electron microscopy) (JEOL, JSM-7000, Japan) techniques. For TEM analysis, few drops of SnAg nano-particle was dispersed in few milliliters of isopropanol in an ultrasonic bath and a drop of this dispersion was placed on a carbon film supported by copper grid. The nanosolders obtained were characterized with an X-ray diffractometer (XRD, Rigaku, DMAX-200/PC).

\section{Results and Discussion}

To understand the effect of reducing agent $\left(\mathrm{NaBH}_{4}\right)$ and stabilizer (PVP) on the chemical reduction process, the amount of $\mathrm{NaBH}_{4}$ and PVP was varied. The experimental results obtained by using different amounts of reducing agent and stabilizer for the synthesis of nano scale Sn-3.5 Ag alloy solder revealed that increased addition of $\mathrm{NaBH}_{4}$ to the bath $(0.01-1 \mathrm{~g})$ transformed the color of the precipitate from grey to black. It might be attributed to the fact that that the reduction reaction was incomplete because of the insufficient amount of reducing agent. For the reduction reaction to be completed, it is essential to keep the reducing agent amount of at least $0.1 \mathrm{~g}$ in this system.

Because chemical reduction technique is employed in this work, hence any chemical reaction resulting in a solvent would consist of three steps: seeding, particle growth, and growth termination by capping. An important process that occurs during the growth of a colloid is Ostwald ripening. Ostwald ripening is a growth mechanism whereby smaller particles dissolve releasing monomers or ions for consumption by larger particles, the driving force being the lower solubility of larger particles. The seeding, nucleation, and termination steps are often not separable and one, therefore, starts with a mixture of the nanocrystal constituents, capping agents, and the solvent. The relative rates of the steps can be altered by changing parameters such as concentration and temperature. One of the important factors that determine the quality of a synthetic procedure is the monodispersity of the nanocrystals obtained. It is desirable to have nanoparticles of nearly the same size, in order to be able to relate the size and the property under study. Hence, the narrower the size distribution, the more attractive is the synthetic procedure. Steric stabilization of hydrosols can be brought about by the use of polymers as stabilizing agents. Natural polymers such as starch and cellulose, synthetic polymers, such as polyvinyl pyrrolidone (PVP), polyvinyl alcohol, and polymethyl vinylether are used as stabilizing agents.

As nano-particles tend to agglomerate together in the SEM images, thus PVP plays an important role in the successful synthesis of the Sn-3.5Ag alloy nanoparticles. SEM image (Figure 1) for Sn-3.5Ag solder alloy obtained without PVP demonstrated that most of the Sn-Ag nanoparticles aggregated into a cluster. Increased addition of PVP $(0.2 \mathrm{~g})$ resulted in stronger aggregation of primary particles. Nevertheless, further increase in the PVP content to $2 \mathrm{~g}$ significantly decreased the agglomeration of nanoparticles and greater dispersion of nanoparticles was noticed (Figure 2). The dispersion of the nanoparticles in the presence of PVP could be attributed to the fact that the protective polymer PVP adsorbed on the nanoparticles and exhibited protective function by steric stabilization [23]. The other part of the protective polymer dissolved in the free-state in the suspension of 


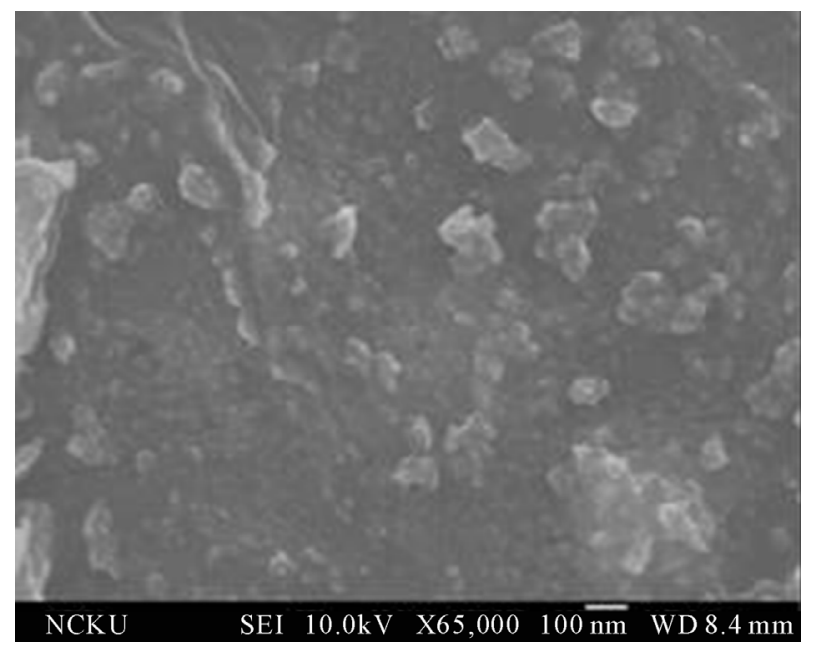

Figure 1. SEM micrograph of Sn-3.5Ag nanoparticles synthesized without PVP.

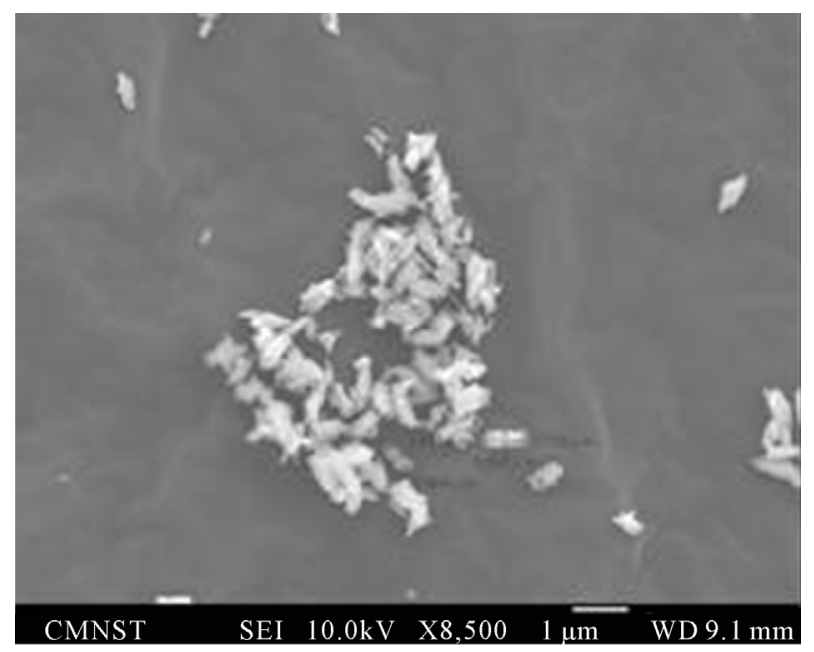

Figure 2. High Magnification SE micrograph of Sn-3.5Ag alloy nanoparticles synthesized with 2 g of PVP.

the alloy nanoparticles as a free polymer. Thus it can be established from the present study that PVP molecules adsorbed on the surface of Sn-Ag nanoparticles and protected against coagulation and precipitation of alloy nanoparticles. It has also been reported [24] that PVP has been used to improve the dispersability of ITO nanoparticles in an aqueous solution. The morphology of Sn$3.5 \mathrm{Ag}$ solder alloy with $2 \mathrm{~g}$ of PVP in the solution was investigated by TEM. The micrograph (Figure 3) revealed a large number of primary particles aggregated strongly to form secondary nanoparticles of larger size. However, discrepancies were seen between SEM and TEM micrographs. The discrepancies might be attributed to the nucleation and particle growth in the related process. As reported by several authors $[25,26]$ the formation of metal atoms after mixing two solutions under rapid

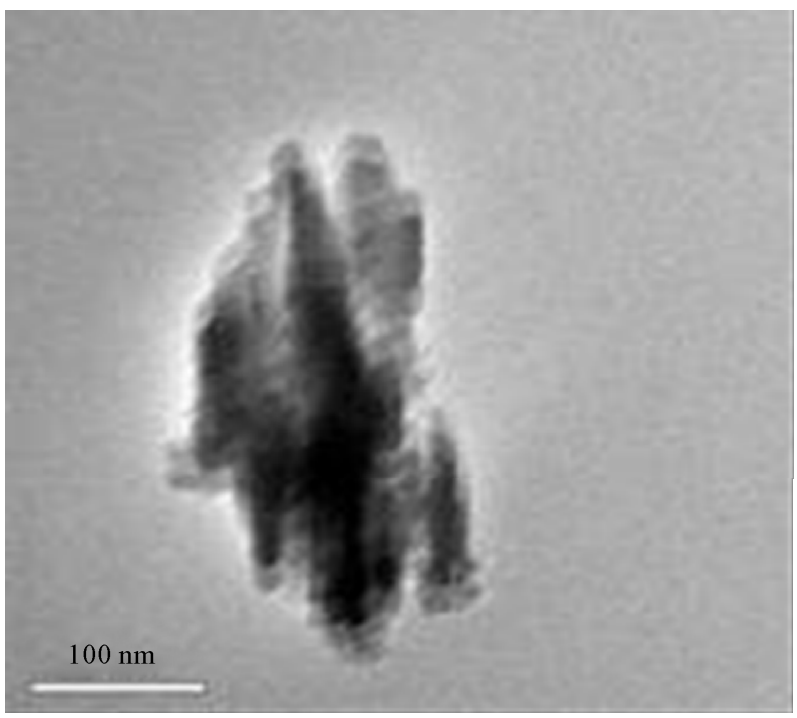

Figure 3. TEM image of Sn-3.5Ag alloy nanoparticles with 2 g of PVP.

stirring resulted from the transfer of electrons from the reducing agent $\mathrm{NaBH}_{4}$ to the metallic ions. The reduction by borohydride has been in existence for a number of years $[27,28]$. The basic reaction involves the hydrolysis of the borohydride accompanied by the evolution of hydrogen.

$$
\mathrm{BH}^{4-}+2 \mathrm{H}_{2} \mathrm{O} \rightarrow \mathrm{BO}_{2}^{-}+4 \mathrm{H}_{2}
$$

Homiyama and coworkers $[29,30]$ made $\mathrm{Cu}$ sols by the borohydride reduction of $\mathrm{Cu}$ (II) salts. Green and O'Brien [31] prepared $\mathrm{Cr}$ and $\mathrm{Ni}$ nanoparticles by carrying out the reduction with $\mathrm{Li}$ or $\mathrm{Na}$ borohydride at high temperatures in coordinating solvents. In the present study a stoichiometric reaction occurs between sodium borohydride and metal precursors was presented in the following reactions below:

$$
\begin{aligned}
\mathrm{BH}^{4-}+8 \mathrm{OH}^{-}+4 \mathrm{Sn}^{2+} \rightarrow \mathrm{B}(\mathrm{OH})_{4-}+4 \mathrm{H}_{2} \mathrm{O}+4 \mathrm{Sn} \\
\mathrm{BH}^{4-}+8 \mathrm{OH}^{-}+8 \mathrm{Ag}^{+} \rightarrow \mathrm{B}(\mathrm{OH})_{4-}+4 \mathrm{H}_{2} \mathrm{O}+8 \mathrm{Ag}
\end{aligned}
$$

The transfer of electrons from the reducing agent to the metal precursors was dependent on the standard redox potential [32] of the two species investigated in our study of the saturation concentration and formed larger nanosize primary particles [33]. As more metal atoms were generated in the system, the primary particles continued to grow by diffusion to form larger crystalline particles or aggregated to form polycrystalline particles.

The XRD pattern for Sn-3.5Ag alloy (Figure 4) exhibited prominent peaks at scattering angles of 30.9, 32.2, $44.1,45.25$ and 55.2 which correspond to scattering from (200) (101) (220) (211) and (301) crystal planes respectively of body centered tetragonal phase of Sn [34]. On the other hand, due to successful alloying of $\mathrm{Sn}$ and $\mathrm{Ag}$, 


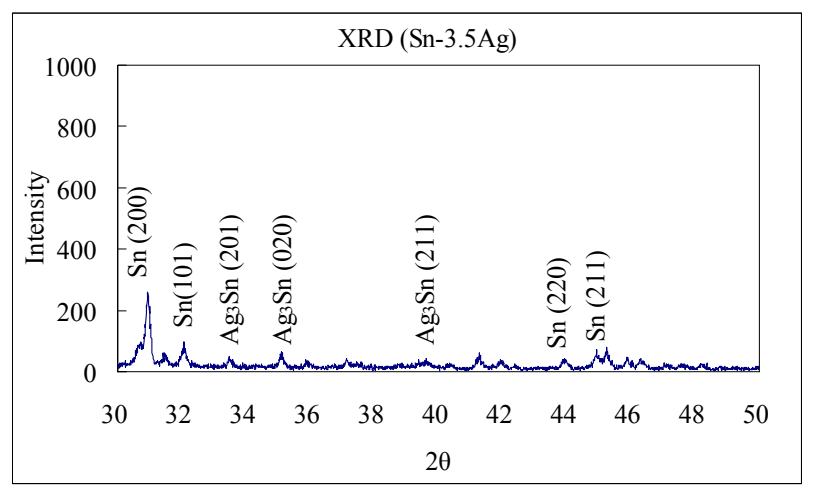

Figure 4. XRD analysis results for Sn-3.5Ag alloy nanoparticles with 2 g PVP.

$\mathrm{Ag}_{3} \mathrm{Sn}$ peaks were observed in the XRD spectrum. Few unwanted reflections were also observed, indicating some impurities, produced during the reduction reaction.

\section{Conclusions}

With well-controlled process parameters, such as the amount of reducing agent and stabilizer, the Sn-3.5Ag alloy nanoparticle could be synthesized successfully by chemical reduction technique. The advantages of chemical reduction reaction are that not only two-component alloy compounds, but also multi-component alloy nanoparticles can be developed by this process.

\section{Acknowledgements}

We are grateful to the Centre of Micro Nanoscience and Technology for providing us the instrumental facilities.

\section{REFERENCES}

[1] S. M. Sze, "VLSI Technology," McGraw-Hill, Boston, 1988.

[2] K. M. Monahan, "Enabling Double Patterning at the 32 nm Node," IEEE International Symposium on Semiconductor Manufacturing, Tokyo, 25-27 September 2006, pp. 126-129. doi:10.1109/ISSM.2006.4493040

[3] I. Artaki, A. M. Jackson and P. T. Vianco, "Evaluation of Lead-Free Solder Joints in Electronic Assemblies," Journal of Electronic Materials, Vol. 23, No. 8, 1994, pp. 757-764. doi:10.1007/BF02651370

[4] P. Pawlow, "Über Die Abhängigkeit des Schmelzpunktes von der Berflächenenergie Eines Festen Körpers," Zeitschrift für Physikalische Chemie, Vol. 65, 1909, pp. 545548.

[5] S. L. Lai, J. Y. Guo, V. Petrova, G. Ramanath and L. H. Allen. "Size-Dependent Melting Properties of Small Tin Particles: Nanocalorimetric Measurements," Physical Review Letters, Vol. 77, No. 1, 1996, pp. 99-102. doi:10.1103/PhysRevLett.77.99

[6] T. Bachels, H. J. Guntherodt and R. Schafer, "Melting of Isolated Tin Nanoparticles," Physical Review Letters, Vol.
85 , No. 6, 2000, pp. $1250-1253$. doi:10.1103/PhysRevLett.85.1250

[7] R. Kofman, P. Cheyssac and F. Celestini, "Comment on Melting of Isolated Tin Nanoparticles," Physical Review Letters, Vol. 86, No. 7, 2001, p. 1388. doi:10.1103/PhysRevLett.86.1388

[8] M. Schmidt, R. Kusche, B. Issendroff and H. Haberland, "Irregular Variations in the Melting Point of Size-Selected Atomic Clusters," Nature, Vol. 393, No. 6682, 1998, pp. 238-240. doi:10.1038/30415

[9] S. J. Zhao, S. Q.Wang, D. Y. Cheng and H. Q. Ye, "Three Distinctive Melting Mechanisms in Isolated Nanoparticles," Journal of Physical Chemistry B, Vol. 105, No. 51, 2001, pp. 12857-12860. doi:10.1021/jp012638i

[10] F. Baletto, A. Rapallo, G. Rossi and R. Ferrando, "Dynamical Effects in the formation of Magic Cluster Structures," Physical Review B, Vol. 69, No. 23, 2004, pp. 235421-235426. doi:10.1103/PhysRevB.69.235421

[11] L. Y. Hsiao and J. G. Duh, "Synthesis and Characterisation of Lead-Free solders by Chemical Reduction Method," Journal of Electrochemical Society, Vol. 152, No. 9, 2005, pp. J105-J109. doi:10.1149/1.1954928

[12] H. B. Bakoglu, "Circuits, Interconnections and Packaging for VLSI, Chapter 2," Addison Wesley, Boston, 1990.

[13] Y. Gaoa, C. Zou, B. Yang, Q. Zhai, J. Liu, E. Zhuravlevd and C. Schick, "Nanoparticles of $\mathrm{SnAgCu}$ Lead-Free Solder Alloy with an Equivalent Melting Temperature of $\mathrm{SnPb}$ Solder Alloy," Journal of Alloy and Compounds, Vol. 484, No. 1-2, 2009, pp. 777-781. doi:10.1016/j.jallcom.2009.05.042

[14] J. Stevanovic, V. Cosovic, J. S. Trosic, B. Jordovic and O. Pesic, Arch Materials Sci, Vol. 28, No. 1, 2007, p. 155.

[15] K. S. Chou and C Y. Ren, "Synthesis of Nanosized Silver Particles by Chemical Reduction Method," Materials Chemistry and Physics, Vol. 64, No. 3, 2000, pp. 241-246. doi:10.1016/S0254-0584(00)00223-6

[16] Y. W. Yen and S. W. Chen, "Phase Equilibria of the AgSn-Cu Ternary System," Journal of Materials Research, Vol. 19, No. 8, 2004, pp. 2298-2305. doi:10.1557/JMR.2004.0296

[17] T. C. Huang, M. C. Wei and H. I. Chen, "Preparation of Hydrogen-Permselective Palladium-Silver Alloy Composite Membranes by Electroless Co-Deposition," Separation and Purification Technology, Vol. 32, No. 1-3, 2003, pp. 239-245. doi:10.1016/S1383-5866(03)00063-7

[18] M. C. Daniel and D. Astruc, "Gold Nanoparticles: Assembly, Supramolecular Chemistry, Quantum-Size-Related Properties, and Applications toward Biology, Catalysis, and Nanotechnology," Chemical Reviews, Vol. 104, No. 1, 2004. pp. 293-346. doi:10.1021/cr030698+

[19] C. Burda, X. Chen, R. Narayanan and M. A. El-Sayed, "The Chemistry and Properties of Nanocrystals of Different Shapes," Chemical Reviews, Vol. 105, No. 4, 2005, pp. 1025-1102. doi:10.1021/cr030063a

[20] B. L. Cushing, V. L. Kolesnichenko and C. J. O'Connor, 
"Recent Advances in the Liquid-Phase Syntheses of Inorganic Nanparticles," Chemical Reviews, Vol. 104, No. 2, 2004, pp. 3893-3946. doi:10.1021/cr030027b

[21] S. Link, Z. L. Wang and M. A. El Sayed, "Alloy Formation of Gold-Silver Nanoparticles and the Dependence of the Plasmon Absorption on Their Composition," Journal of Physical Chemistry B, Vol. 103, No. 18, 1999, pp. 3529-3533. doi:10.1021/jp990387w

[22] M. A. Yang, M. A. Winter and J. O. Besenhard, "Small Particle Size Multiphase Li-Alloy Anodes for LithiumIon-Batteries," Solid State Ionics, Vol. 90, No. 1-4, 1996, pp. 281-287. doi:10.1016/S0167-2738(96)00389-X

[23] B. Yin, H. Ma, S. Wang and S. Chen, "Electrochemical Synthesis of Silver Nanoparticles under Protection of Poly(N-Vinylpyrrolidone)," Journal of Physical Chemistry B, Vol. 107, No. 34, 2003, pp. 8898-8904. doi:10.1021/jp0349031

[24] J. E. Song, D. K. Lee, Y. H. Kim and Y. S. Kang, "Preparation of Water Dispersed Indium Tin Oxide Sol Solution," Molecular Crystals and Liquid Crystals, Vol. 444, No. 1. 2006, pp. 247-255. doi:10.1080/15421400500365078

[25] A. Corrias, G. Ennas, G. Licheri, G. Marongiu and G. Paschina, "Amorphous Metallic Alloy Powders Prepared by Chemical Reduction of Metal Ions with Potassium Borohydride in Aqueous Solution," Chemistry of Materials, Vol. 2, No. 4, 1990, pp. 363-366. doi:10.1021/cm00010a010

[26] D. Zeng and M. J. Hampden-Smith, "Synthesis and Characterization of Nanophase Group 6 Metal (M) and Metal Carbide (M2C) Powders by chemical Reduction Methods," Chemistry of Materials, Vol. 5, No. 5, 1993, pp. 681-689. doi:10.1021/cm00029a018
[27] H. I. Schlesinger, H. C. Brown, A. E. Finholt, J. R. Gilbreath, H. R. Kockstra and E. K. Hyde, "Sodium Borohydride, Its Hydrolysis and Its Use as a Reducing Agent and in the Generation of Hydrogen," Journal of American Chemical Society, Vol. 75, No. 1, 1953, pp. 215-219. doi:10.1021/ja01097a057

[28] H. C. Brown and C. A. Brown, "New Highly Active Metal Catalysts for the Hydrolysis of Borohydride," Journal of American Chemical Society, Vol. 84, No. 8, 1962, pp. 14931494. doi:10.1021/ja00867a034

[29] H. Hirai, H. Wakabayashi and M. Komiyama, "Polymer-Protected Copper Colloids as Catalysts for Selective Hydration of Acrylonitrile," Chemistry Letters, Vol. 12, No. 7, 1983, pp. 1047-1050. doi:10.1246/cl.1983.1047

[30] H. Hirai, H. Wakabayashi and M. Komiyama, "Preparation of Polymer Protected Colloidal Dispersion of Copper," Bulletin of the Chemical Society of Japan, Vol. 59, No. 2, 1986, pp. 367-372. doi:10.1246/bcsj.59.367

[31] M. Green and P. O. Brien, "The Preparation of Organically Functionalised Chromium and Nickel Nano Particles," Chemical Communications, Vol. 29, No. 19, 2001, pp. 1912-1913. doi:10.1039/b107108b

[32] M. Pourbaix, "Atlas of Electrochemical Equilibria in Aqueous Solutions," Oxford University Press, New York, 1974.

[33] Y. Zhao, Z. Zhang and H. Dang, "Preparation of Tin Nanoparticles by Solution Dispersion," Materials Science and Engineering A, Vol. 359, No. 1-2, 2003, pp. 405-407. doi:10.1016/S0921-5093(03)00395-2

[34] D. V. Goia, "Preparation and Formation Mechanisms of Uniform Metallic Particles in Homogeneous Solutions," Journal of Materials Chemistry, Vol. 14, No. 4, 2004, pp. 451-458. 